\title{
The Split Margin Approach to Syllable Structure
}

\author{
Karen Baertsch and Stuart Davis \\ Southern Illinois University at Carbondale and Indiana University \\ kbaertsc@siu.edu and davis@indiana.edu
}

\section{$1 \quad$ Introduction}

In this paper we focus on the similarities tying together the second segment of an onset cluster and a singleton coda segment. We offer a proposal based on Baertsch (2002) accounting for this similarity and show how it captures a number of observations which have defied previous explanation. In accounting for the similarity of patterning between the second member of an onset and a coda consonant, we propose to augment Prince \& Smolensky's (P\&S, 1993/2002) Margin Hierarchy so as to distinguish between structural positions that prefer low sonority and those that prefer high sonority. P\&S's Margin Hierarchy, which gives preference to segments of low sonority, applies to singleton onsets; this is our $\mathrm{M}_{1}$ hierarchy. Our proposed $\mathrm{M}_{2}$ hierarchy applies both to the second member of an onset and to a singleton coda. The $\mathrm{M}_{2}$ hierarchy differs from the $\mathrm{M}_{1}$ hierarchy in giving preference to consonants of high sonority. Splitting the Margin Hierarchy into the $\mathrm{M}_{1}$ and $\mathrm{M}_{2}$ hierarchies allows us to explain typological, phonotactic, and acquisitional observations that have defied previous explanation. In Section 2 of this paper, we briefly provide background on the links that tie together the second member of an onset and a singleton coda. In Section 3, we review P\&S's Margin Hierarchy, showing that it becomes problematic when extended to coda consonants. We then offer our proposal for a split margin hierarchy. Section 4 extends the split margin approach to complex onsets. We then show how it is able to account for various typological, phonotactic, and acquisitional observations. In Section 5, we will conclude the paper by briefly sketching how the split margin approach enables us to analyze syllable contact phenomena without requiring a specific syllable contact constraint (or additional hierarchy) or reference to an external sonority scale.

\section{The links between the second member of an onset and a singleton coda}

There are a number of phonological phenomena from typology, acquisition and phonotactics that point to a similarity in patterning between a coda consonant and the second member of an onset. One relatively well-known manifestation of this similarity comes from work on sonority such as that of Clements (1990) where it is observed that there is a preference for low sonority segments as a singleton onset and high sonority consonants as a singleton coda. In onset clusters, though, the preference is for a low sonority consonant followed by one of high sonority. This follows from the Sonority Sequencing Principle (Selkirk 1982, Blevins 1995, among others) which holds that sonority rises in moving from the beginning of the syllable toward the peak. As a result, clusters of an obstruent plus a glide or liquid are

Earlier versions of this paper were presented at the Manchester Phonology Meeting in May 2003, at the Leiden sonorants workshop in September 2003 and at ZAS in October 2003. We thank the attendees of those talks for their comments, but especially Laura Downing, Tonio Green, T. A. Hall, Silke Hamann, Barbara Stiebels and Sabine Zerbian. 
common among languages that allow onset clusters, while obstruent plus nasal or nasal plus liquid clusters are less common. Consequently, both the second member of an onset and a singleton coda prefer consonants of high sonority. (To be clear, in our discussion of onset clusters we do not consider the matter of sibilant-plus-stop clusters which we do not consider to be proper onset clusters. While these clusters can occur word-initially in many languages, they frequently display behavior that distinguishes them phonologically from other syllableinitial clusters and are often best analyzed with the sibilant being adjoined at a higher level of prosody, or, perhaps, in the case of /st/ clusters as single segments. See Bagemihl 1991, Davis 1990, and Selkirk 1982 for analyses regarding s-clusters in different languages, and Barlow 1997 for the developmental difference between s-clusters and other initial clusters in child phonology.)

A further manifestation of the similarity of patterning between the second member of an onset and a coda comes from the structure of syllable inventories, both in fully developed languages and in first language acquisition. Kaye and Lowenstamm (1981) observe that if a language permits onset clusters (i.e. CCV syllables) then it must have CVC syllables, but the reverse is not true; a language can have CVC syllables without permitting CCV syllables. That is, the presence of an onset cluster in a language implies the presence of a coda consonant. This characteristic is also reflected in the first language acquisition of structural slots within the syllable. As noted by Lleó and Prinz (1996) and Levelt, Schiller, and Levelt (1999), CV syllables commonly appear first in acquisition, followed by CVC syllables and finally onset clusters. This order is something that can be formally explained if there is a link between coda segments and second onset segments. The link between onset cluster and coda in acquisition can also involve the specific quality of the segment. An interesting case of this comes from Fikkert (1994). In this study, Jarmo, a child acquiring Dutch as his first language, has liquids as second members of onsets and as singleton codas at around the age of 24 months, but does not have liquids as single onset consonants at this age. From one perspective, such a pattern seems odd since one might assume that the presence of a liquid as a second member of an onset cluster would imply its presence as a singleton onset, but that implication does not hold in acquisition.

Finally, we find phenomena from phonotactics that suggest a link between the second member of an onset and a coda as well. There are some fairly well-known examples of constraints against words with identical consonants flanking the nuclear vowel only when the word begins with an onset cluster - not when the word begins with a single consonant. For example, as noted by researchers such as Clements and Keyser (1983), Davis (1988), and Fudge (1969), English lacks syllables like *[p1D] but allows for ones like [1t]. In other words, the constraint is against a syllable where the second onset segment and the first coda segment are identical.

In the next section we will focus on the high sonority preference for coda consonants and offer our split margin proposal whereby the coda is governed by the $\mathrm{M}_{2}$ hierarchy which gives preference to high sonority consonants. In Section 4 we extend the split margin approach to complex onsets showing how it is able to explain the similarity of patterning between the second onset segment and a singleton coda.

\section{Syllable Margins in Optimality Theory - The Split Margin Proposal}

In order to put our split margin proposal in context, we will begin with a short overview of Prince and Smolensky's (1993/2002) analysis of onset segments. P\&S give us the familiar constraints in (1a) along with their Margin Hierarchy in (1b). This accounts nicely for the 
behavior of onsets, encoding both the preference to have an onset in the first place (the ONSET constraint) and the preference for low sonority segments to fill onset position (the Margin Hierarchy). We will call P\&S's Margin Hierarchy the $\mathrm{M}_{1}$ hierarchy to distinguish it from our proposed $\mathrm{M}_{2}$ hierarchy. Note here that we do not include glides as a separate category in the $\mathrm{M}_{1}$ hierarchy. We treat glides and high vowels both as [+hi] vocalic segments.

(1) Syllable margins (onsets)
a. Onset encourages syllables with onsets
ONSET $>>$ FAITH onsets are required
FAITH $>$ ONSET $\quad$ onsets are optional
b. Margin Hierarchy (M1) incorporates the preference for low sonority onsets. $* \mathrm{M}_{1} /[+\mathrm{lo}]>>* \mathrm{M}_{1} /[+\mathrm{hi}]>>* \mathrm{M}_{1} /[\mathrm{r}]>>* \mathrm{M}_{1} /[1]>>* \mathrm{M}_{1} / \mathrm{Nas}>>\mathrm{M}_{1} / \mathrm{Obs}$

The preference for low sonority onsets is reflected typologically by a number of languages in which high sonority segments are avoided in onsets. For example, in the Siberian (Turkic) language Yakut in (2), both [r] and [j] are systematically avoided in onset position (Baertsch 2003b, based on data from Schönig 1988, Krueger 1962, and Kharitonov 1982). They do not occur word-initially, do not occur as the second consonant in a two-consonant word-medial cluster (Yakut does not allow onset clusters), and they do not occur as geminates. Other consonants can fill these positions. The segments [r] and [j] do occur as codas and intervocalically. We analyze intervocalic instances of $[\mathrm{r}]$ and [j] as standing in coda position, which is consistent with how Yakut borrows Russian words that begin with these sounds as shown in (2). An initial [r], when encountered in a borrowing, takes a prothetic vowel and an initial [j] hardens to [ $\left.\mathrm{d}^{\mathrm{j}}\right]$ (2a). Medial VCrV and VCjV clusters are simplified (2c). Given this distribution, the two most sonorous consonants of Yakut are banned in onset position, reflecting a $* \mathrm{M}_{1} /[+\mathrm{hi}]>* \mathrm{M}_{1} /[\mathrm{r}]>>$ FAITH constraint ranking.

(2) Distribution of Yakut $[\mathrm{r}]$ and $[\mathrm{j}]$
a. Initial $/ \mathrm{r} /, / \mathrm{j} /$ disallowed
Yakut [äriäntä] < Russian rénta 'rent'
[d[lolka] < ëlka 'fir, Xmas tree'
b. $\quad[\mathrm{r}]$ and $[\mathrm{j}]$ allowed as codas
[ïar] 'heavy'
[iij] 'moon, month'
c. $\quad$ Medial *VC.rV, *VC.jV clusters disallowed
Yakut [kuudara] < Russian kúdri 'curls'
[bïlaatt[ija] < plat'e 'dress, gown'
[sibii[Dä] $<\quad$ svín’ja 'pig'

The situation in Gujarati, an Indo-Aryan language of India, shown in (3) is similar (de Lacy 2001, based on data from Cardona 1965). Here, the labial glide is a dispreferred onset and has an obstruent allophone [v] that appears in onset position (3a). [w] is freely parsed in coda position and can occur as the second member of an onset cluster. Intervocalically, [w] and [v] are in free variation (3c). We would analyze the free variation as reflecting variation in the syllabification as well as variation in surface segments: [w] surfaces when the segment is parsed as a coda and [v] surfaces when the segment is parsed as an onset. 
(3)

Distribution of Gujarati [w] and [v]
a. $\quad[\mathrm{w}]$ is neutralized to [v] initially: [vat] *[wat] 'matter, story'
b. [w] can appear in codas: [Daw] 'cow'
c. $\quad[\mathrm{w}]$ is in free variation with [v] intervocalically: [s】war] [s】var] 'morning'

One way the low sonority preference for onsets manifests itself in first language acquisition is in the order of acquisition of onset consonants. It is commonly the case that the first onsets a child acquires are stops with more sonorous segments being acquired in this position at later stages. Before the more sonorous segments are acquired, we often find high sonority underlying segments surfacing as lower sonority segments. We find exactly this pattern in Fikkert's (1994: 57-62) data on Jarmo's acquisition of Dutch in (4). Jarmo initially produced stop onsets, which were later followed by nasals, then liquids, then glides. When substitutions occurred (both before and after those segments first appeared target appropriately), the surface segment was less sonorous than the underlying segment. This acquisition pattern is straightforwardly accounted for by the gradual demotion of the $\mathrm{M}_{1}$ constraints below the relevant faithfulness constraint.

(4) Acquisition of Dutch onsets

a. Stop onsets are present at $1 ; 4$

daar /dalt/ [da] 'there' 1;4.18

b. $\quad$ Nasal onsets begin to appear after 1;9

\begin{tabular}{|c|c|c|c|c|}
\hline meer & /mę/ & [mil] & 'more' & $2 ; 0.28$ \\
\hline muis & $/ \mathrm{m}$ ys/ & {$\left[\begin{array}{ll}p & y s\end{array}\right]$} & 'mouse' & $2 ; 1.22$ \\
\hline regen & /remb(n)/ & [tem0] & 'rain' & $1 ; 11.20$ \\
\hline
\end{tabular}

c. $\quad$ Liquid onsets acquired after $2 ; 1$

\begin{tabular}{|c|c|c|c|}
\hline leeuw /leظw/ & {$[\mathrm{le} \downarrow \mathrm{v}]$} & 'lion' & $2 ; 1.22$ \\
\hline 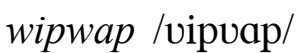 & [piф口] & 'seesaw' & $1 ; 8.12$ \\
\hline & [liфpa] & & $2 ; 1.8$ \\
\hline
\end{tabular}

d. Glides appear after 2;3

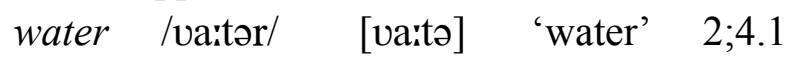

When we extend P\&S's Margin Hierarchy to the analysis of codas, we run into difficulty given the preference for high sonority coda segments, which we assume to be independent of the issue of coda moraicity (for example, the presence of a coda in Yakut does not interact with stress placement or vowel length). P\&S's Margin Hierarchy encodes preference for low sonority consonants, not high sonority ones. This difficulty is mentioned by P\&S (§8.3.2) who conclude that the treatment of the coda is yet to be fully explored in OT. Let us detail the problem and offer a proposal. NoCODA is the only constraint available in P\&S that is analogous to ONSET. NOCODA is similar to ONSET in that it makes a categorical determination about codas as a unit (shown in 5a). The ranking of NoCoDA with respect to FAITH determines whether codas are allowed or banned.

(5) Syllable margins (codas)

a. NoCoda discourages or bans codas

NoCODA $>>$ FAITH codas are banned

FAITH $>$ NoCODA codas are optional 
b. NoCoda explodes into the M2 hierarchy

$$
* \mathrm{M}_{2} / \mathrm{Obs}>* \mathrm{M}_{2} / \mathrm{Nas}>>\mathrm{M}_{2} /[1]>* \mathrm{M}_{2} /[\mathrm{r}] \gg * \mathrm{M}_{2} /[+\mathrm{hi}]>* \mathrm{M}_{2} /[+\mathrm{lo}]
$$

NoCODA is also similar to the $\mathrm{M}_{1}$ hierarchy in that it is negatively phrased, militating against codas just as the $\mathrm{M}_{1}$ hierarchy militates against particular segments filling onset position. The major drawback to NoCODA is that it cannot account for the segmental content of codas. Coupling NoCODA with Prince \& Smolensky's Margin Hierarchy would result in a preference for low sonority rather than high sonority codas when codas are allowed. We propose that the NOCODA constraint is the encapsulation of a second margin hierarchy, the $\mathrm{M}_{2}$ hierarchy in (5b), which does incorporate the high sonority preference. The ranking of this hierarchy is the reverse of the $M_{1}$ hierarchy, making obstruents the most marked segments in coda position and high sonority segments the least marked codas (Baertsch 2002).

Exploding NoCODA in this way gives us the tools we need to analyze the segmental content of coda segments while the absence of a coda counterpart to the ONSET constraint (a constraint that would encourage syllables with codas as ONSET encourages syllables with onsets) still ensures that codas are dispreferred in general.

We want to be clear that our proposed $\mathrm{M}_{2}$ hierarchy in (5b) does not give preference for vowels in the coda, even though the $\mathrm{M}_{2}$ constraint governing low vowels is the lowest ranked constraint in the hierarchy. The $\mathrm{M}_{2}$ hierarchy interacts with the Peak hierarchy, and the comparatively low ranking nature of the $* \mathrm{P} /$ Vowel constraints causes a vowel to be pulled into the nucleus rather than being parsed as a coda. However, we do find in some languages, like English and Dutch, that long vowels and diphthongs seem to spill over into the $\mathrm{M}_{2}$ position rather than being encased completely in the nucleus (cf. Baertsch 2002 for more detailed discussion of this point).

If we reconsider the Yakut case in (2), the ranking $* \mathrm{M}_{1}[+\mathrm{hi}]>>\mathrm{M}_{1} /[\mathrm{r}]>>$ FAITH prevents [r] and [j] from surfacing in onset position. If that were the end of it, we would never see [r] as a surface margin segment in this language (unless, of course, [r] could fill the peak, which it cannot in Yakut). Any instance of underlying / $r /$ would force some violation of FAITH in the winning candidate. Incorporating the $\mathrm{M}_{2}$ hierarchy into the analysis offers another option: parsing an underlying $/ \mathrm{r} /$ as a coda. In this way, we can account for the insertion of the prothetic vowel in [r]-initial borrowings (2a) as providing a nucleus to which a coda $[\mathrm{r}]$ may attach with the constraint ranking $* \mathrm{M}_{1}[\mathrm{r}]>>$ DEP $>>* \mathrm{M}_{2} /[\mathrm{r}]$.

A second example of the interaction of segmental content with coda position comes from Randall Gess's (1998) analysis of coda loss in Old French. We have included some of his data in (6). Essentially, codas with sonority equal to or greater than alveolar fricatives were deleted with compensatory lengthening of the preceding vowel.

Coda loss in Old French

\begin{tabular}{|c|c|c|c|}
\hline & ca. 1050 & ca. 1200 & gloss \\
\hline barde & [bardc] & 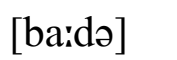 & 'pack' \\
\hline albe & [albD] & [awbD] & 'dawn' \\
\hline ante & [a日tD] & [alt] & 'aunt' \\
\hline blasmer & [blazmer] & [bla[mer] & 'to blame' \\
\hline
\end{tabular}

Gess considers and rejects a NoCODA analysis of these data precisely because NoCODA cannot deal with the sonority facts of the change, including the fact that the change stopped short of [r] in some dialects. If NoCODA explodes into the $\mathrm{M}_{2}$ hierarchy, this is no longer a 
problem. The loss of codas over time represents a change in the relative position of FAITH with respect to the $\mathrm{M}_{2}$ hierarchy. In the early constraint ranking, FAITH is ranked between the $\mathrm{M}_{2}$ constraint militating against very low sonority consonants (represented as $* \mathrm{M}_{2} / \mathrm{T}$ in the constraint ranking) and the $\mathrm{M}_{2}$ constraint militating against alveolar fricatives $\left(* \mathrm{M}_{2} / \mathrm{S}\right.$ in the constraint ranking). At the later stage, FAITH is between $* \mathrm{M}_{2} /[\mathrm{r}]$ and $* \mathrm{M}_{2} /[+$ hi $]$ as in (7).

$$
\begin{aligned}
& \text { Old French constraint ranking } \\
& * \mathrm{M} 2 / \mathrm{T}>>\text { Faith }>>* \mathrm{M} 2 / \mathrm{S}>>* \mathrm{M} 2 / \mathrm{Nas}>>* \mathrm{M} 2 /[1]>{ }_{\uparrow}>\mathrm{M} 2 /[\mathrm{r}] \underset{\uparrow}{>}>\mathrm{M} 2 /[+\mathrm{hi}]
\end{aligned}
$$

In the dialects in which coda [r] was not included in the change, FAITH dominates $* \mathrm{M}_{2} /[\mathrm{r}]$. In the other dialects, ${ }^{*} \mathrm{M}_{2} /[\mathrm{r}]$ dominates FAITH. The compensatory lengthening is a result of the underlying segments being realized as vocalic, thus violating the $\mathrm{M}_{2}$ constraints still dominated by FAITH.

It is also not uncommon to find languages in which low sonority segments, for example obstruents, are banned from coda position while high sonority segments are acceptable codas. Examples include Ponapean (Goodman 1995) and Sranan (Alber \& Plag 2001, based largely on data from Smith 1987). Consider the Sranan data in (8).

(8) Sranan codas

$\begin{array}{lllll}\text { ku.ne.ti } & \text { 'goodnight' } & \text { tran.ga } & \text { 'strong' } & \text { shar.ki 'shark' } \\ \text { sa.fri } & \text { 'softly' } & \text { mem.re } & \text { 'remember' } & \text { mar.ki 'mark' }\end{array}$

Here, obstruents but not sonorants are banned from coda position. Nasals are apparently the most common coda segments, but several examples of coda [r] are given as well. Since English is the lexifier language for this Creole, it is faced with many illicit obstruent codas that must be eliminated. Medially, coda obstruents in Sranan are often deleted and wordfinally, they are made syllabifiable by the addition of a nuclear vowel, as in the 'goodnight' example in (8). On our approach, the $* \mathrm{M}_{2} / \mathrm{Obs}$ constraint in Sranan dominates FAITH and the remainder of the $\mathrm{M}_{2}$ hierarchy is dominated by FAITH $\left(* \mathrm{M}_{2} / \mathrm{Obs}>>\right.$ FAITH $\left.>>* \mathrm{M}_{2} / \mathrm{Nas} \ldots\right)$.

It is also worth noting that in acquisition, early codas are often high sonority segments, although the picture in acquisition is somewhat muddied by the problem of wordfinal consonants and their status as codas or as extrasyllabic segments (cf. Piggott 1999). For example, Fikkert's (1994: 171-172) account of the Dutch child Jarmo finds that the first word internal codas produced by this child are sonorants as in (9). He seems to avoid attempts at medial obstruent codas.

\begin{tabular}{|c|c|c|c|c|}
\hline drinken & 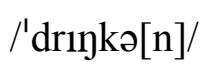 & 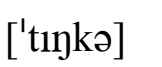 & 'to drink' & $2 ; 2.6$ \\
\hline Selma & /[\$lma[ & [面lma[] & name & $2 ; 3.9$ \\
\hline
\end{tabular}

(9) Word medial consonant clusters in acquisition (Jarmo)

Similarly, consider the data in (10) from Martohardjono (1989) which documents Jenny's acquisition of English.

(10) Medial clusters in English (Jenny at age 3;2)

a. Obstruent clusters are simplified: /VO.OV/ becomes [V.OV]

toothpaste [tu.pe footprints [f].p[hs]

b. Nasal-Obstruent clusters surface: /VN.OV/ surfaces as [VN.OV]
blanket
$[\mathrm{b} \square$ n.t $\square \mathrm{t}]$
rainbow [re $\mathrm{m} . \mathrm{bo}]$ 
Here, we see that Jenny deletes word-internal obstruent codas in (10a) but retains word internal nasal codas in (10b). Word final obstruents do surface in this case and we would analyze these segments as $\mathrm{M}_{1}$ (onset) segments following Piggott (1999). The analysis of these developing systems would be similar to Sranan in (8) where the $* \mathrm{M}_{2} / \mathrm{Obs}$ constraint dominates FAITH and the remainder of the $\mathrm{M}_{2}$ hierarchy is dominated by FAITH.

\section{The extension of the $M_{2}$ hierarchy to complex onsets and the links to the coda}

Like single coda consonants, there is a preference for high sonority segments to fill the second member of an onset cluster. And like single coda segments, P\&S's single Margin Hierarchy does not straightforwardly account for the sonority contour of onset clusters. Within OT, onset clusters have most commonly been examined in the past through constraints encoding a sonority distance requirement along with a language-specific sonority scale or by more specific (and more ad-hoc) constraints whose purpose is simply to ban a particular cluster outright. Here we propose that the $\mathrm{M}_{2}$ hierarchy in (5b), shown to govern coda positions, also governs the second member of an onset. We repeat the $\mathrm{M}_{2}$ hierarchy in (11b). Like NOCODA and the margin constraints, *COMPLEX is negatively phrased, militating against complex onsets wherever it happens to fall in the hierarchy (11a). What is missing from *COMPLEX is a mechanism that can judge the segmental content of a cluster as the margin constraints can.

(11) Syllable margins (complex onsets)

a. $\quad *$ Complex discourages or bans complex onsets

*COMPLEX $>>$ FAITH complex onsets are banned

FAITH $>$ * COMPLEX complex onsets are optional

b. $\quad * \mathrm{M} 2 / \mathrm{Obs}>>$ M $2 / \mathrm{Nas}>>* \mathrm{M} 2 /[1]>>\mathrm{M} 2 /[\mathrm{r}]>>$ M $2 /[+\mathrm{hi}]>>\mathrm{M} 2 /[+\mathrm{lo}]$

We propose here that the $\mathrm{M}_{2}$ hierarchy, in combination with the $\mathrm{M}_{1}$ hierarchy can do just that (and can replace ${ }^{*}$ COMPLEX). The $\mathrm{M}_{1}$ hierarchy governs the first segment on an onset cluster and the $\mathrm{M}_{2}$ hierarchy governs the second member. By having the $\mathrm{M}_{2}$ hierarchy apply to both the second member of an onset and to the coda, we immediately account for the high sonority preference of both of these positions. Moreover, the other links mentioned in Section 2 between the second member of an onset and a coda, namely the phonotactic, acquisitional, and typological links that tie these positions together can be explained under our split margin approach. In this section we first consider some of the simpler analyses of the split margin approach to explain phonotactic links and some links in acquisition between these two positions. We then turn to the analysis of onset clusters through the conjunction of the margin hierarchies in order to offer insight to the typological link discussed in Section 2 whereby the presence of a complex onset in a language presupposes the presence of a coda in that language.

In Section 2 we mentioned the fairly well-known examples of phonotactic constraints against words with identical consonants flanking the nuclear vowel only when the word begins with an onset cluster - not when the word begins with a single consonant. These have been noted for English by researchers such as Clements and Keyser (1983), Davis (1988), and Fudge (1969) and for Dutch by Booij (1995: 42-47) and we show some examples for both languages in (12). 
Cooccurrence phenomena

a. English: OCP holds over M2

Identical $\mathrm{M}_{2}$ within the syllable: $*\left[\mathrm{p}_{1} \mathrm{l}_{2} \mathrm{Q}_{2}\right], *\left[\mathrm{p}_{1} \mathrm{l}_{2} \mathrm{Z}_{2} \mathrm{p}_{1}\right]$

Identical $\mathrm{M}_{1}$ within the syllable: Lyle $\left[\mathrm{l}_{1} \mathrm{aj}_{2} \mathrm{l}_{1}\right]$, klunk $\left[\mathrm{k}_{1} \mathrm{l}_{2} \Lambda \mathrm{D}_{2} \mathrm{k}_{1}\right]$

Identical $\mathrm{M}_{1}$ and $\mathrm{M}_{2}$ within a syllable: loll $\left[\mathrm{l}_{1} \mathrm{al}_{2}\right]$, lilt $\left[\mathrm{1}_{1} \mathrm{Q}_{2} \mathrm{t}_{1}\right]$, clock $\left[\mathrm{k}_{1} \mathrm{l}_{2} \mathrm{ak}_{2}\right]$

b. Dutch: OCP holds over both M2 and M1

*/ $\mathrm{C}_{1} \mathrm{l}_{2} \mathrm{Vl}_{2} /:$ * plol, ${ }^{*}$ klol, *blol, *slol

$/ 1_{1} \mathrm{VV}_{2} 1_{1} /$ is 'strange': *lool, *leel, *laal, *luul, *loel, *liel

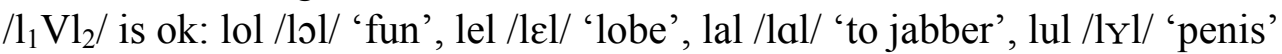

For example, English disallows syllables like *[plD] but allows syllables like [1Dt]. The difference between these two syllables from our perspective is that both instances of [1] in *[p10] are in $\mathrm{M}_{2}$ position while in [1[t] the first [1] is in $\mathrm{M}_{1}$ position and the second is in $\mathrm{M}_{2}$ position. In showing the English and Dutch data in (12) we have indicated by the use of subscript numerals whether each margin segment constitutes an $\mathrm{M}_{1}$ or $\mathrm{M}_{2}$ position. What clearly emerges from this is that the phonotactic constraint can be viewed as an OCP type constraint holding over identical $\mathrm{M}_{2}$ segments within a syllable. (We analyze coda clusters as essentially the reverse of onset clusters - an $\mathrm{M}_{2}$ segment followed by an $\mathrm{M}_{1}$ segment.)

The constraint in Dutch is similar to English in that identical $\mathrm{M}_{2}$ segments within a syllable do not occur. Dutch may have a similar constraint against identical $\mathrm{M}_{1}$ segments within a syllable as shown in (12b), although these data are complicated by the data with $/ \mathrm{r} /$. Forms including identical $\mathrm{M}_{1}$ rhotics do occur (raar/raar/ 'strange', roer/ruur/ 'rudder') suggesting to us that the strangeness of $/ l_{1} \mathrm{VV}_{2} 1_{1} /$ in Dutch may be due to something other than a constraint against identical $\mathrm{M}_{1}$ segments, in which case Dutch will be just like English in banning only identical $\mathrm{M}_{2}$ segments within the syllable. While there are further issues of detail in the cross-vowel phonotactics of both English and Dutch that we do not explore here, the split margin hierarchy is able to offer an explanation for why such phonotactic constraints occur at all.

Another situation where our split margin hierarchy can account for a phenomenon that has defied previous explanation comes from first language acquisition where it has sometimes been remarked that children may acquire segments in complex onsets before acquiring them as single onsets. A striking case of this comes from the acquisition of Dutch by Jarmo reported by Fikkert (1994), though the discussion here is based on that of Baertsch (2002) which proposes a rhyme structure for these data that differs from Fikkert's. Jarmo begins to produce onset clusters consisting of an obstruent followed by a liquid several months before producing singleton liquid onsets. From one perspective, this pattern seems odd. If rhotics and laterals can occur as the second member of an onset, shouldn't they also appear as a singleton onset? Our response to this question is no. Given our analysis, there is no expectation that a segment must be allowed as a singleton onset (an $\mathrm{M}_{1}$ position) before occurring as the second segment in an onset cluster (an $\mathrm{M}_{2}$ position). We would, however, expect to see a connection between when segments begin to appear as singleton codas and in second onset position because both are $\mathrm{M}_{2}$ position. And Jarmo's pattern of acquisition supports our expectation. He acquires onset clusters at roughly the same time he acquires sonorant codas. On our analysis, Jarmo had demoted the $* \mathrm{M}_{1} / \mathrm{Nasal}$ and $* \mathrm{M}_{1} /$ Obstruent constraints below FAITH at this point in time, allowing obstruents and nasals to surface as onsets and had also demoted $* \mathrm{M}_{2} / \mathrm{Nasal}$ and $* \mathrm{M}_{2} /$ Liquid below FAITH allowing sonorants to surface in the available $\mathrm{M}_{2}$ positions. 
Thus, the split margin hierarchy can account for developing phonology like that witnessed in Jarmo where there is a close link between the second member of an onset and the coda. The presence of a consonant as a second member of an onset need not imply its presence as a singleton onset.

There are two questions that emerge from our discussion and analysis of Jarmo's system, First, can there be a fully developed phonology like Jarmo's in which some segments can appear in $\mathrm{M}_{2}$ but not in $\mathrm{M}_{1}$ position? We argued in Section 3 that Yakut is one such language, where [r] and [j] surface only in $\mathrm{M}_{2}$ (coda) position (cf. (2) above). And Gujarati, in (3) above allows [w] in both $\mathrm{M}_{2}$ positions (coda and second onset position) but not in $\mathrm{M}_{1}$ position. Possible additional languages to consider would be those Australian languages such as Arrernte (Breen and Pensalfini 1999) which are claimed to lack onsets. Second, do we claim that it should always be the case in acquisition that in languages with onset clusters, the acquisition pattern would always be the one displayed by Jarmo where there is a stage in which the child has a sonorant as a second member of an onset without having it as a singleton onset? Here the answer is clearly no. As a specific example, consider the discussion of the acquisition of Greek by the child Sofia discussed in Kappa (2002, 2003). Between the age of 1 year 10 months and 2 years 10 months Sofia acquired all the single onset consonants of Greek with no sonority restrictions. During the same period Sofia did not produce onset clusters. She also did not have any (word-internal) coda consonants. From our perspective, this system can be analyzed with the entire $\mathrm{M}_{1}$ hierarchy ranked below FAITH and the entire $\mathrm{M}_{2}$ hierarchy ranked above FAITH.

This ranking prevents the realization of any $\mathrm{M}_{2}$ consonant but allows for the realization of any consonant in $\mathrm{M}_{1}$ position. Thus, on this ranking of the two margin hierarchies with respect to the faithfulness constraints, all consonants are allowed as singleton onsets before any of them appear as second member of an onset, thus contrasting with Jarmo's system.

We now turn to the link from syllable typology that connects the coda with the second member of an onset. As mentioned in Section 2, Kaye and Lowenstamm (1981) observe that if a language permits onset clusters (i.e. CCV syllables) then it must have CVC syllables, but the reverse is not true; a language can have CVC syllables without permitting CCV syllables. That is, the presence of an onset cluster in a language implies the presence of a coda consonant. While we are aware of possible counterexamples to this implication, they seem to be rare and often subject to a reanalysis of the apparent onset cluster. (For example, Kaye 1985 argues that the liquid in a CLV sequence in Vata patterns as an element of a rising diphthong while Steriade 1994 argues for a single segment approach to apparent complex onsets in Mazateco.) As far as we are aware, this implication has defied explanation. We show here that the implication follows logically given our split margin approach to the syllable. To see this, we must first digress to detail how the specific nature of onset clusters is accounted for under the split margin approach.

In the split margin approach to the syllable (as developed in Baertsch 2002), the nature of onset clusters is accounted for by conjunction of the $M_{1}$ and the $M_{2}$ hierarchies. Through exhaustive conjunction of these two hierarchies, we generate a set of constraints that addresses the sonority relationship between the two segments of every possible onset cluster. We list a small part of the conjoined hierarchy in (13).

(13) The conjoined margin hierarchy

$$
\ldots>>\text { Obs } 1 \& N a s 2>>\text { Obs } 1 \&[1] 2>>* O b s 1 \&[\mathrm{r}] 2>>* \text { Obs } 1 \&[+\mathrm{hi}] 2 \ldots
$$


In these constraints, the $\mathrm{M}_{1}$ component has been listed first and abbreviated simply to ${ }^{*} \mathrm{Obs}_{1}$ for $* \mathrm{M}_{1} / \mathrm{Obs}$, and so on. The $\mathrm{M}_{2}$ component is listed second using the same abbreviation format. So the first constraint in (13), ${ }^{*} \mathrm{Obs}_{1} \& \mathrm{Nas}_{2}$, is violated by an output onset cluster consisting of an initial obstruent followed by a nasal and so on. There are two important points to note about these constraints. Firstly, the domain for these conjunctions is adjacent $\mathrm{M}_{1}$ and $\mathrm{M}_{2}$ segments within a syllable and the order of the two segments is not specified. Therefore, the same constraint, say $* \mathrm{Obs}_{1} \&[1]_{2}$ would potentially govern an onset cluster consisting of an obstruent plus [1] or a coda cluster consisting of an [1] followed by an obstruent since coda clusters will be the mirror image of onset clusters. To be clear, however, we do not predict that occurring coda clusters in a language should always be only the mirror image of occurring onset clusters. Additional constraints such as OCP constraints also affect these clusters. Our discussion here necessarily focuses only on onset clusters. Secondly, conjunction inherits some of the ranking relationships of the component constraints. This is shown in (14) for a subset of the conjoined constraints and follows Downing (1998), Itô \& Mester (1998), Smolensky (1993), Spaelti (1997) and others.

\section{Ranking of conjunctions}

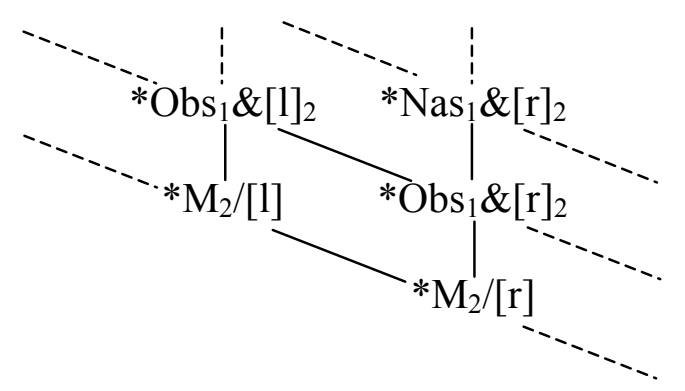

A conjoined constraint dominates both of its component constraints, so the conjoined constraint $* \mathrm{Obs}_{1} \&[1]_{2}$ would have to dominate both $* \mathrm{M}_{1} / \mathrm{Obs}$ and $* \mathrm{M}_{2} /[1]$. In addition, two conjoined constraints that share one component constraint, like ${ }^{*} \mathrm{Obs}_{1} \&[1]_{2}$ and ${ }^{*} \mathrm{Obs}_{1} \&[\mathrm{r}]_{2}$, inherit the ranking of the component that differs, in this case $* \mathrm{M}_{2} /[1]$ outranks $* \mathrm{M}_{2} /[\mathrm{r}]$ so $* \mathrm{Obs}_{1} \&[1]_{2}$ outranks $* \mathrm{Obs}_{1} \&[\mathrm{r}]_{2}$. What these two ranking arguments do for the conjunction of the two hierarchies is to automatically impose upon the set of conjoined constraints a ranking that would predict exactly what we find typologically. The least marked clusters (based on the lowest ranking constraints) are clusters consisting of an obstruent plus a liquid or glide - the types of clusters that are common cross-linguistically. More marked clusters like obstruent plus nasal or nasal plus [r] clusters are governed by conjunctions that dominate the obstruent plus liquid conjunctions. Equal sonority clusters are governed by even higher ranking constraints and falling sonority (onset) clusters even higher. In other words, conjunction of the two hierarchies gives us the markedness facts and the sonority sequencing principle without having to impose a constraint ranking on it - the ranking is inherited along with the component constraints. (A side issue that arises is the matter of vocalic segments in the conjoined hierarchies. If we are conjoining the whole of the $\mathrm{M}_{2}$ hierarchy to the complete $\mathrm{M}_{1}$ hierarchy and the lowest ranking constraint on the $\mathrm{M}_{2}$ hierarchy is $* \mathrm{M}_{2} /[-\mathrm{hi}]$, shouldn't that make clusters of obstruent plus non-high vowel the best clusters? As we mentioned earlier, the $\mathrm{M}_{2}$ hierarchy interacts with the Peak hierarchy. Vocalic segments that could potentially be $\mathrm{M}_{2}$ segments within an onset cluster are pulled into the nucleus instead by the Peak constraints. The issue of the potential ambiguous behavior of high vowels as peaks or margins is beyond the scope of the present paper.) 
We give a more concrete example from Spanish to illustrate how the conjunction of the two margin hierarchies gives us the preferred onset clusters as an obstruent plus liquid (or glide) without having to impose sonority sequencing or sonority distance constraints. In Spanish, as shown by the data in (15a), obstruent plus liquid sequences are allowed as onsets but potential obstruent plus obstruent onset sequences are not allowed and can be eliminated by prothesis as shown in (15b).

(15) Exemplification from Spanish (only obstruent + sonorant onsets are allowed)
a. /blanko/
[blaロ.ko]
'white'
b. /sposa/
[es.po.sa]
'wife'

The different outcomes of the two (potential) initial onset clusters in (15) can be accounted for with the ranking in (16) where the relevant Faithfulness constraint (DEP) is ranked between the high ranking conjoined constraint that rules out two obstruents and the lower ranked one that militates against an obstruent-liquid cluster.

(16) Constraint ranking for Spanish:

*Obs1\&Obs2 >> Dep >> *Obs1\&*[1]2, *M2/Obs >> *M2/[1], *M1/Obs

As explained above, the conjoined constraint $* \mathrm{Obs}_{1} \& \mathrm{Obs}_{2}$ must be intrinsically ranked higher than the conjoined constraint ${ }^{*} \mathrm{Obs}_{1} \& *[1]_{2}$ because of their difference in the $\mathrm{M}_{2}$ conjuncts $-{ }^{*} \mathrm{M}_{2} / \mathrm{Obs}$ outranks $* \mathrm{M}_{2} /[1]$. We give tableaux in (17) and (18) for the data in (15) to make clear our analysis.

Complex onset (Spanish)
/bla[ko/ $[$ bla_.ko]
\begin{tabular}{|l||c|c|c|c|c|c|}
\hline$/$ bla/ & $* \mathrm{Obs}_{1} \& \mathrm{Obs}_{2}$ & $\mathrm{DEP}$ & $* \mathrm{Obs}_{1} \&[1]_{2}$ & $* \mathrm{M}_{2} / \mathrm{Obs}$ & $* \mathrm{M}_{2} /[1]$ & $* \mathrm{M}_{1} / \mathrm{Obs}$ \\
\hline \hline bla & & & $*$ & & $*$ & $*$ \\
\hline eb.la & & $* !$ & & $*$ & & \\
\hline
\end{tabular}

Prothetic vowel (Spanish)

/sposa/ [es.po.sa]
\begin{tabular}{|l||c|c|c|c|c|c|}
\hline$/$ spo/ & $* \mathrm{Obs}_{1} \& \mathrm{Obs}_{2}$ & $\mathrm{DEP}$ & $* \mathrm{Obs}_{1} \&[1]_{2}$ & $* \mathrm{M}_{2} / \mathrm{Obs}$ & $* \mathrm{M}_{2} /[1]$ & $* \mathrm{M}_{1} / \mathrm{Obs}$ \\
\hline \hline spo & $* !$ & & & & & $*$ \\
\hline es.po & & $*$ & & $*$ & & $*$ \\
\hline
\end{tabular}

We thus see that the conjunction of the two margin hierarchies can account for the preferred onset cluster of an obstruent plus sonorant without the need for imposing sonority sequencing or sonority distance constraints or even imposing an external sonority hierarchy. Crucially, it is the use of the $\mathrm{M}_{2}$ hierarchy for determining acceptability of coda segments combined with the use of the same $\mathrm{M}_{2}$ hierarchy through constraint conjunction to account for the acceptability of onset clusters that links the two syllable positions together. What follows as a natural consequence of this is the implication noted by Kaye and Lowenstamm (1981) that the presence of onset clusters in a language implies the presence of codas. This is because if a conjoined $* \mathrm{M}_{1} \& * \mathrm{M}_{2}$ constraint is ranked below FAITH so as to permit the $\mathrm{M}_{1} \& \mathrm{M}_{2}$ onset cluster, then, necessarily, by the logic of constraint conjunction, the corresponding $* \mathrm{M}_{2}$ conjunct must be even lower ranked which allows for that single $\mathrm{M}_{2}$ segment in a coda. Thus, considering the Spanish example in (17), the faithfulness constraint DEP outranks 
$* \mathrm{Obs}_{1} \& *[1]_{2}$ permitting the complex obstruent plus [1] onset, and $* \mathrm{Obs}_{1} \& *[1]_{2}$ outranks $* \mathrm{M}_{2} /[1]$, allowing the singleton coda [1]. Notice that our split margin approach also accounts for the fact that there are many languages that have codas which lack complex onsets. In such a language the $\mathrm{M}_{2}$ hierarchy would be ranked below FAITH allowing for codas, but the conjoined $\mathrm{M}_{1}$ and $\mathrm{M}_{2}$ hierarchies would be ranked above FAITH. This is shown in (19) and is the situation in Yakut, discussed above.

(19) The constraint ranking for a language with codas but lacking complex onsets

$$
\text { *M1\&M2 >> Faith }>>* \mathrm{M} 2
$$

We view this as a strong point of the split margin approach. It formally accounts for Kaye and Lowenstamm's implication that the presence of an onset cluster in a language implies the presence of codas and we note that the approach developed here can be formally extended to account for the observation noted by Lleó and Prinz (1996) and Levelt, Schiller, and Levelt (1999) that CV syllables appear first in acquisition, followed by CVC syllables and finally onset clusters.

\section{Conclusion}

In this paper we have focused on the similarities tying together the second segment of an onset cluster and a singleton coda segment. We have offered a proposal based on Baertsch (2002) that splits the Margin Hierarchy of Prince \& Smolensky (1993/2002) so as to distinguish between structural positions that prefer low sonority and those that prefer high sonority. Our proposed $\mathrm{M}_{1}$ hierarchy gives preference to segments of low sonority and applies to singleton onsets; our proposed $\mathrm{M}_{2}$ hierarchy applies both to the second member of an onset and to a singleton coda and gives preference to consonants of high sonority. As we have shown in this paper, splitting the Margin Hierarchy into the $M_{1} \& M_{2}$ hierarchies allows us to explain various typological, phonotactic, and acquisitional observations that have defied previous explanation.

There are a variety of implications that emerge from our approach that we do not pursue here. This includes the possible analysis of a word final consonant as either an $\mathrm{M}_{1}$ or $\mathrm{M}_{2}$ segment, thus accounting for Piggott's (1999) delineation that final consonants in some languages are coda-like (an $\mathrm{M}_{2}$ segment on our analysis) and in other languages onset-like (an $\mathrm{M}_{1}$ segment on our analysis). It also includes the possible analyses of on-glides in different languages (and within the same language) as either onset segments or peak segments given the tension between the low-ranking Peak and $\mathrm{M}_{2}$ constraints both of which favor high vowels (see, for example, Davis and Hammond 1995 and Baertsch 2003a for English.) Finally, as developed in Baertsch (2002), the split margin approach can account for syllable contact effects (i.e. the preference to avoid rising sonority over a syllable boundary) without the need for additional syllable contact constraints. Syllable contact effects are handled much like complex onsets but within a larger domain. Consider one example of this, namely Bat-El's (1996) discussion of Modern Hebrew blends. Bat-El shows that the sonority profile is a crucial factor in determining the linear order of component monosyllabic elements in blends. For example, the blend of the Hebrew words [xay] 'alive' and [bar] 'wild' could hypothetically be either *[barxay] or [xaybar] 'wildlife safari', only the latter of which is correct. While Bat-El proposes both a syllable contact constraint and a syllable contact slope constraint our split margin approach readily accounts for this given that a coda is in $\mathrm{M}_{2}$ position and prefers a higher sonority consonant and a single onset is in $\mathrm{M}_{1}$ position preferring a consonant of low sonority. Consider the tableau in (20). 
xáy 'alive, he lives' plus bár 'wild' = xaybár *barxay

\begin{tabular}{|l|c|c|c|c:c|}
\hline & $* \mathrm{Obs}_{1} \&[\mathrm{r}]_{2}$ & $* \mathrm{Obs}_{1} \&[+\mathrm{hi}]_{2}$ & $* \mathrm{M}_{2} /[\mathrm{r}]$ & $* \mathrm{M}_{2} /[+\mathrm{hi}]$ & $* \mathrm{M}_{1} / \mathrm{Obs}$ \\
\hline \hline xaybár & & $*$ & $*$ & $*$ & $* *$ \\
\hline barxay & $* !$ & & $*$ & $*$ & $* *$ \\
\hline
\end{tabular}

Conjunction of the $\mathrm{M}_{1}$ and $\mathrm{M}_{2}$ hierarchies over the domain of the word, in addition to the syllable domain relevant for complex margins discussed earlier, will select the candidate with the larger sonority fall as shown in (20). Thus, our split margin proposal can account for syllable contact effects without reference to specific syllable contact constraints or other sonority distance constraints.

\section{References}

Alber, B. \& Plag, I. 2001. Epenthesis, deletion and the emergence of the optimal syllable in creole: The case of Sranan. Lingua 111,8: 11-40.

Baertsch, K. 2002. An Optimality Theoretic Approach to Syllable Structure: The Split Margin Hierarchy. Ph.D. dissertation of Indiana University.

Baertsch, K. 2003a. The resolution of English CiV vs. CuV sequences. Manuscript, Southern Illinois University at Carbondale.

Baertsch, K. 2003b. The syllabification of high sonority consonants in Yakut. Paper presented at MidContinental Workshop on Phonology 9, University of Illinois at Urbana-Champaign.

Bagemihl, B. 1991. Syllable structure in Bella Coola. Linguistic Inquiry 22: 589-646.

Barlow, J. 1997. A Constraint-Based Account of Syllable Onsets: Evidence from Developing Systems. Ph.D. dissertation of Indiana University.

Bat-El, O. 1996. Selecting the best of the worst: The grammar of Hebrew blends. Phonology 13: 283-328.

Blevins, J. 1995. The syllable in phonological theory. In: J. Goldsmith (ed.) The Handbook of Phonological Theory. Cambridge, MA: Blackwell; 206-44.

Booij, G. 1995. The Phonology of Dutch. Oxford: Oxford University Press.

Breen, G. and Pensalfini, R. 1999. Arrernte: A language with no syllable onsets. Linguistic Inquiry 30: 1-25.

Cardona, G. 1965. Gujarati Reference Grammar. Philadelphia: University of Philadelphia Press.

Clements, G. N. 1990. The role of the sonority cycle in core syllabification. J. Kingston \& M. Beckman (eds.) Papers in Laboratory Phonology 1: Between the Grammar and Physics of Speech. New York: Cambridge University Press; 283-333.

Clements, G. N. \& Keyser, S. 1983. CV Phonology: A Generative Theory of the Syllable. Cambridge, MA: MIT Press.

Davis, S. 1988. Topics in Syllable Geometry. New York \& London: Garland.

Davis, S. 1990. The onset as a constituent of the syllable: Evidence from Italian. In: M. Ziolkowski, M. Noske \& K. Deaton (eds.) Papers from the Parasession of CLS 26:2 on the Syllable in Phonetics \& Phonology. Chicago, IL: Chicago Linguistic Society; 71-79.

Davis, S. and Hammond, M. 1995. On the status of onglides in American English. Phonology 12,1: 59-82.

de Lacy, P. 2001. Prosodic markedness in prominent positions. ROA 432. U Mass, Amherst.

Downing, L. 1998. On the prosodic misalignment of onsetless syllables. Natural Language and Linguistic Theory 16: 1-52.

Fikkert, P. 1994. On the Acquisition of Prosodic Structure. The Hague: Holland Academic Graphics.

Fudge, E. C. 1969. Syllables. Journal of Linguistics, 5,2: 53-86.

Gess, R. 1998. Old French NoCoda effects from constraint interaction. Probus 10,2: 7-18.

Goodman, B. 1995. Features in Ponapean phonology. Ph.D. dissertation of the Cornell University.

Itô, J. and Mester, A. 1998. Markedness and word structure: OCP effects in Japanese. ROA-255. UC Santa Cruz. 
Kappa, I. 2002. On the acquisition of syllable structure in Greek. Journal of Greek Linguistics, 3: 1-52.

Kappa, I. 2003. Reduction and coalescence: A conspiracy resolving the violations of *Complex. Paper presented at the First Old World Conference on Phonology (OCP 1), University of Leiden, Leiden, Holland, January 9-11.

Kaye, J. 1985. On the syllable structure of certain West African languages. In : D. Goyvaerts (ed.) African Linguistics: Essays in Memory of M. W. K. Semikenke. Philadelphia: John Benjamins; 285-307.

Kaye, J. \& Lowenstamm, J. 1981. Syllable structure and markedness theory. Theory of markedness in generative grammar. In: A. Belletti, L. Brandi \& L. Rizzi (eds.) Proceedings of the 1979 GLOW Conference, Pisa, Italy: Scuola normale superiore di Pisa; 287-315.

Kharitonov, L. N. 1982. Grammatika sovremennogo jakutskogo literaturnogo jazyka [Grammar of the Modern Yakut Literary Language]. Moskva: Izdatel'stvo Nauka'.

Krueger, J. 1962. Yakut Manual. Bloomington, IN and The Hague, Netherlands: Indiana University and Mouton $\&$ Co.

Levelt, C., Schiller, N. \& Levelt, W. 1999. A developmental grammar for syllable structure in the production of child language. Brain and Language 68.2: 91-99.

Lleó, C. \& Prinz, M. 1996. Consonant clusters in child phonology and the directionality of syllable structure assignment. Journal of Child Language 23: 31-56.

Martohardjono, G. 1989. The sonority cycle in the acquisition of phonology. Papers and Reports on Child Language Development 28.1: 31-39.

Piggott, G. L. 1999. At the right edge of words. The Linguistic Review, 16.1: 43-85.

Prince, A. \& Smolensky, P. 1993/2002. Optimality Theory: Constraint Interaction in Generative Grammar. ROA 537; Rutgers University \& Johns Hopkins University.

Schönig, C. 1988. Zum Vokalismus russischer Lehnwörter im Jakutischen [On the vowel system of Russian loanwords in Jakut]. Ural-Altaische Jahrbücher 8,1: 25-36.

Selkirk, E. 1982. The syllable. In: H. v. d. Hulst \& N. Smith (eds.) The Structure of Phonological Representations (Part II). Dordrecht: Foris Publications; 337-83.

Smith, N. 1987. The Genesis of the Creole Languages of Surinam. Ph.D. dissertation of the University of Amsterdam,

Smolensky, P. 1993. Harmony, markedness, and phonological activity. Paper presented at Rutgers Optimality Workshop 1, October 23, 1993.

Spaelti, P. 1997. Dimensions of Variation in Multi-Pattern Reduplication. Ph.D. dissertation of the University of California, Santa Cruz.

Steriade, D. 1994. Complex onsets as single segments: The Mazateco pattern. In: J. Cole \& C. Kisseberth (eds.) Perspectives in Phonology. Stanford: Center for the Study of Language and Information; 203-91. 